\title{
THE DETECTION AND ESTIMATION OF HERITABLE DIFFERENCES IN BEHAVIOUR AMONG INDIVIDUALS*
}

\author{
J. L. JINKS and P. L. BROADHURST \\ ARC Unit of Biometrical Genetics and Deportment of Anotomy, \\ University of Birminghom
}

Received $7 \cdot x \cdot 64$

\section{INTRODUCTION}

THE last few years have seen an increasing application of the experimental designs and analytical procedures of biometrical genetics to the study of the inheritance of behavioural differences (see, for example, Broadhurst, 1959, I 960; Broadhurst and Jinks, I96I, I963; Fuller and Thompson, 1960). The procedures so far adopted in psychogenetics, however, have generally been based on crosses between strains. In such crosses replicate, reciprocal and multiple matings are possible because each strain can be represented in the crossing programme by a number of individuals of each sex. Such procedures, while necessarily restricted in their application to a few wellestablished laboratory and domestic animals, have a number of advantages. For example, reciprocal matings provide an estimate of maternal effects and the effects of sex linkage; replicate matings provide an estimate of environment differences between families (the $E_{2}$ of Mather, I 949) as well as providing larger progenies from each kind of mating. Furthermore, they provide estimates of the effects associated with the passage of time, for example, birth order and maternal age, or allow their effects to be avoided by using a different female for each cross.

The most important advantage from the interpretative point of view, however, is that interstrain crosses provide data of a kind suitable for testing both the adequacy of the scale and of the assumptions upon which the validity of the analyses and the interpretations based on them depend (Mather, I949).

Nevertheless, there are many situations, both in the laboratory and among non-laboratory (e.g. human) populations, where such strains are not available. What can be done towards investigating the inheritance of continuously varying characters where strains and breeds are not available, that is, where the animals available for crossing, or who have adventitiously mated together already, are a collection of miscellaneous individuals of varying or, indeed, unknown relationships? The present paper compares a number of the simpler biometrical analyses which have been developed, and we shall illustrate the analyses with some behavioural and morphological characteristics of laboratory rates, the inheritance of which has already been

* This work was supported in part by U.S. Public Health Service Research Grant No. MHo8 712 from the National Institute of Mental Health. 
extensively investigated by crosses between inbred strains (Broadhurst, ı 960 ; Jinks and Broadhurst, I963; Broadhurst and Jinks, I964b).

\section{MATERIALS AND METHODS}

The illustrative material derives from 336 offspring born from matings among 14 male and 17 female rats (Rattus norvegicus Berkenhout). These animals were chosen as parents because they wcre a representative sample of the variation available in the laboratory at that time. Thus they comprised individual rats from several inbred strains and some $F_{1}$ crosses between them. Each male was involved in at least two different matings, the maximum number involving a single father being five. Each female was also mated to two different males, this number being exceeded only when matings were repeated to increase the number of progeny available. In fact, the experiment was planned as a series of $2 \times 2$ diallel crosses in which each individual (as opposed to the more usual strain) was mated in every possible combination, thus generating four separate families (as opposed to the more usual $F_{1}$ hybrids). When proved fertile, parents were used more than once, but only to the extent noted above. As a consequence we can extract not only four $2 \times 2$ diallels but also two $2 \times 3$ partial diallels from among the successful matings. In all, 34 of the matings were successful in producing litters, some at least of which survived to maturity, though these represent only a portion of the total attempted.

The $3^{1}$ parents of all the successful crosses and all the surviving progeny of the crosses were weighed at various ages, and 19 of the parents and, again, all the surviving progeny were tested for the behavioural traits of emotional elimination, in the form of defecation, and exploratory ambulation in an open field. Since there is no significant correlation between the parents of the successful crosses for any of these three measures, we shall assume that they represent a random sample of all possible crosses between the parents.

All animals were reared and tested in a standardised manner, and the details of the experimental techniques and animal husbandry used are given elsewhere (Broadhurst, I96o, pp. 30-43).

\section{RESULTS}

\section{(i) Parity}

An inevitable consequence of our experimental design is that litters may differ in parity and hence also in the age and weight of the mother at the time of birth. To avoid confounding the effects of parity and these correlated characters with other non-heritable causes of differences between litters (see later), we have carried out a number of preliminary analyses. The parities of the litters range from one to four, the higher parities being the result of repeating some of the crosses (see section 2 above) and the use of some mothers in earlier, unrelated experiments. An analysis of variance of the defecation scores in which differences among litters are partitioned into between and within parity items is given in table I. The analysis shows that there are highly significant differences between litters ( $\mathrm{P}<0.00 \mathrm{I}$ for both sexes) but that neither the total differences between parities nor a linear regression on parity is significantly greater than the differences between litters of the same parity.

The same analysis for ambulation scores and for body weight at birth, at weaning (2 I days) and at maturity (around roo days) leads to 
similar conclusions. Thus parity differences are not an important source of differences between litters in the present data.

TABLE I

Anulysis of variance of defecation scores to detect differences among offspring due to parity of mother

\begin{tabular}{|c|c|c|c|}
\hline Item & d.f. & $\begin{array}{c}\text { Males } \\
\text { MS }\end{array}$ & $\begin{array}{c}\text { Females } \\
\text { MS }\end{array}$ \\
\hline $\begin{array}{l}\text { 1. Between litters } \\
\text { (a) Between parities. } \\
\text { (i) Linear regression } \\
\text { (ii) Remainder } \\
\text { (b) Within parities } \\
\text { 2. Within litters }\end{array}$ & $\begin{array}{c}32^{*} \\
3 \\
1 \\
2 \\
29 \\
111 \dagger\end{array}$ & $\begin{array}{r}35 \cdot 27 \\
16 \cdot 50 \\
20 \cdot 78 \\
14 \cdot 36 \\
37 \cdot 21 \\
1 \cdot 52\end{array}$ & $\begin{array}{r}20 \cdot 34 \\
6 \cdot 65 \\
14 \cdot 05 \\
2 \cdot 90 \\
21 \cdot 76 \\
0 \cdot 39\end{array}$ \\
\hline
\end{tabular}

* One litter out of the total of 34 contained males only and one, females only.

+ in 4 d.f. for females.

(ii) Components of variation

Within and between litter variation.

In the absence of significant parity effects the analysis of variance is reducible to two items, the between litters mean square and the within litters mean square. These can be equated directly with the expected components of variance $\sigma_{\mathrm{B}}^{2}$ (between families) and $\sigma_{\mathrm{W}}^{2}$ (within families) in the following way:

\begin{tabular}{|c|c|c|c|}
\hline & & Males & Females \\
\hline $\begin{array}{l}\text { Between litters MS } \\
\text { Within litters MS }\end{array}$ & . & $\sigma \underset{\mathrm{W}}{\stackrel{2}{\mathrm{~W}}}+4 \cdot 1806 \sigma \stackrel{2}{\mathrm{~B}}$ & $\begin{array}{l}\sigma \underset{W}{2}+-3 \cdot 9^{8} 32 \sigma^{2} \\
\sigma_{W}^{2}\end{array}$ \\
\hline
\end{tabular}

where the coefficients of $\sigma_{\mathrm{B}}^{2}$ have been obtained by the niethod of Snedecor (1956) for litters of unequal size. Our estimates of $\sigma_{\mathrm{W}}^{2}$ and $\sigma_{\mathrm{B}}^{2}\left(\mathrm{~V}_{\mathrm{w}}\right.$ and $\mathrm{V}_{\mathrm{B}}$ of the defecation scores obtained) are, therefore,

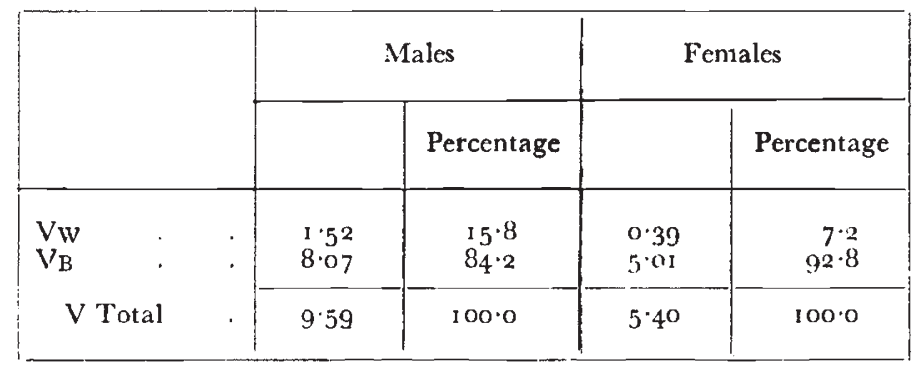

Because of the large relative magnitude of the sex interaction for defecation, the components of variance for this character are given separately for each sex in this and in all subsequent analyses. For the 
other two measures, ambulation and mature body weight, the sex interaction is relatively so small that in most of the analyses the variance components have been averaged over sexes.

If we assume that the heritable components of variation involve only additive and dominance effects, we can express the expectation of $\sigma_{\mathrm{W}}^{2}$ and $\sigma_{\mathrm{B}}^{2}$ in terms of $\mathrm{D}_{\mathrm{R}}$ and $\mathrm{H}_{\mathrm{R}}$, the random mating forms of the additive and dominance components of variation respectively (Mather, 1949). Thus

$$
\begin{aligned}
& \sigma_{\mathrm{B}}^{2}=\frac{(\mathrm{I}+f)}{4} \mathrm{D}_{\mathrm{R}}+\left(\frac{\mathrm{I}+f}{4}-\right)^{2} \mathrm{H}_{\mathrm{R}}+\mathrm{E}_{2}-\frac{\mathrm{I}}{n} \mathrm{E}_{1} \\
& \sigma_{\mathrm{W}}^{2}=\frac{(\mathrm{I}-f)}{4} \mathrm{D}_{\mathrm{R}}+\frac{(\mathrm{I}-f)(3+f)}{\mathrm{I} 6} \mathrm{H}_{\mathrm{R}}+\mathrm{E}_{1} \\
& \sigma_{\mathrm{T}}^{2}=\frac{1}{2} \mathrm{D}_{\mathrm{R}}+\frac{1}{4} \mathrm{H}_{\mathrm{R}}+\mathrm{E}_{\mathbf{2}}+\frac{n-\mathrm{I}}{n} \mathrm{E}_{1}
\end{aligned}
$$

where $\mathrm{D}_{\mathrm{R}}=\Sigma_{4} u v[d+(v-u) h]^{2}$

$\mathrm{H}_{\mathrm{R}}=\Sigma_{\mathrm{I}} 6 u^{2} v^{2} h^{2}$

and $\quad \mathrm{E}_{1}=$ non-heritable component of variation within litters.

$\mathrm{E}_{2}=$ non-heritable component of variation between litters which in the design adopted in the present paper includes, in addition to the usual environmental factors, all effects of time due to the matings involving any one female parent occurring in sequence. However, we have already shown that one possible component, namely, parity and hence age of mother, with which it is inevitably correlated, are unimportant sources of variation in the material used (see section 3.i above).

$f=$ coefficient of inbreeding (Wright, I92 I).

$n=$ mean litter size, suitably adjusted for variation between litters (see Dickinson and Jinks (1956), Cockerham (1956) and Kempthorne (1957) for the derivation of these expectations).

Clearly we cannot estimate any of these unknowns from the observed values of $\mathrm{V}_{\mathrm{w}}$ and $\mathrm{V}_{\mathrm{B}}$ without making some simplifying assumptions. Furthermore, we cannot obtain a valid estimate of heritability of the defecation response unless we assume that the environmental variation between litters is the same order of magnitude as that within litters, that is, $\mathrm{E}_{2}=\frac{\mathrm{I}}{n} \mathrm{E}_{1}$.

On the other hand, since the origin of every parental animal used in the experiment is known, we can compute an expected value of $f$ for each sex (see Falconer, I96o, p. 9I) and hence simplify the expectations for $\sigma_{\mathrm{B}}^{2}, \sigma_{\mathrm{W}}^{2}$ and $\sigma_{\mathrm{T}}^{2}$. The values obtained for $f$ are 0.92 for males and 0.98 for females and may be regarded for practical purposes as equal to $\mathrm{I}$. A further indication that $f$ is high comes from the observed values of the ratio $\frac{V_{B}}{V_{T}}$ which equals 0.84 for males and 0.93 for females. The maximum value that can be obtained for this ratio depends on the 
value of $f$. For example, if $f==\mathrm{I}$ the maximum value is I while if $f=0$ the maximum value is $\frac{1}{2}$. The relationship between the maximum value of $\frac{\mathrm{V}_{\mathrm{B}}}{\mathrm{V}_{\mathrm{T}}}$ and $f$ assuming $\mathrm{H}_{\mathrm{R}}=\mathrm{o}$ and $\mathrm{D}_{\mathrm{r}}=\mathrm{H}_{\mathrm{R}}$ is shown in fig. $\mathrm{I}$. Reference to this figure shows that values of $\frac{V_{B}}{V_{T}}$ as high as thosc observed

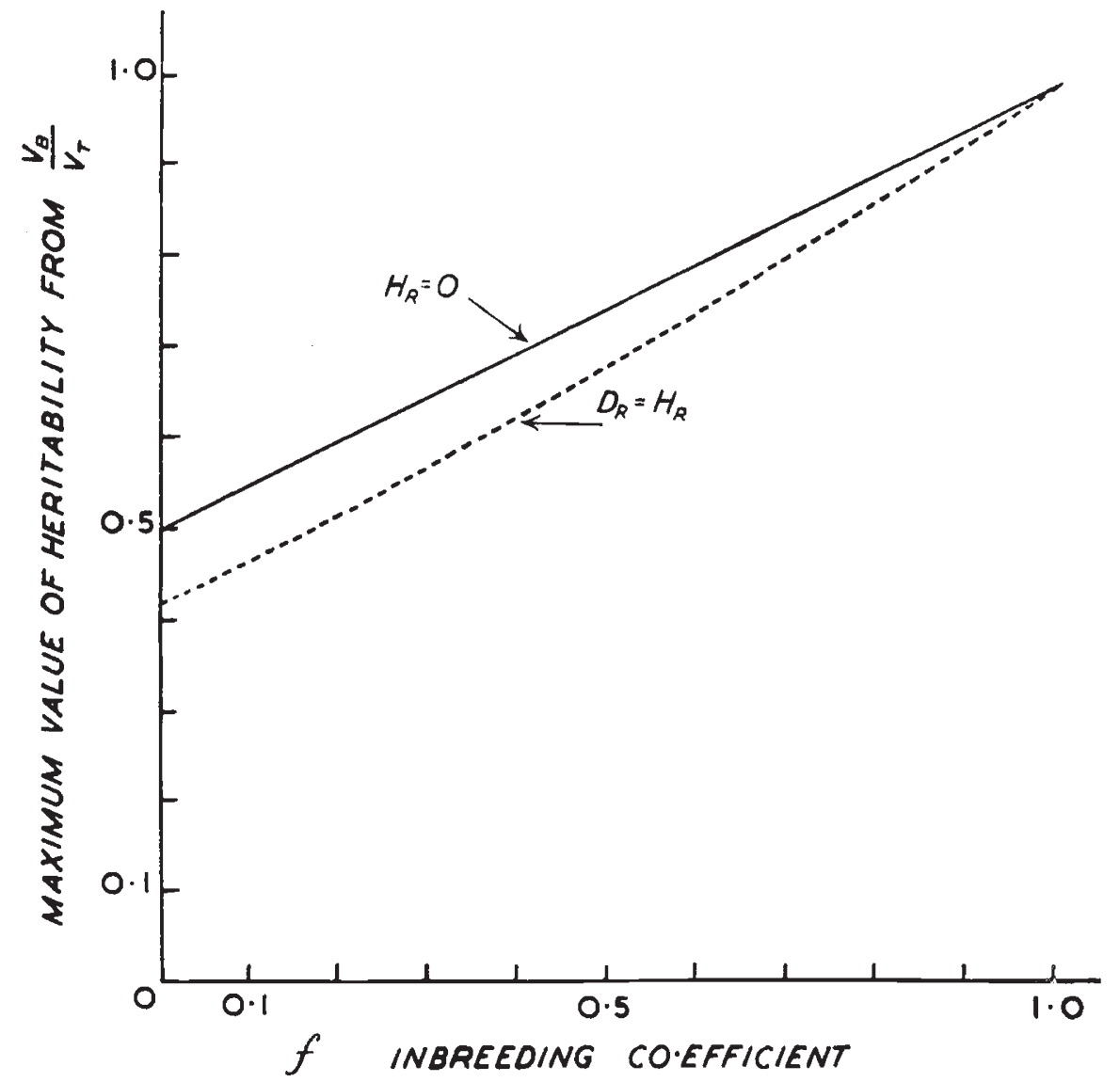

Frc. I.-Relationship between heritability measured as $\frac{V_{3}}{V_{S}}$ and co-efficient of inbreeding.

could not be obtained unless $f$ is higher than 0.68 and 0.85 respectively since lower values of $f$ would imply more than roo per cent. heritability for the defecation measure.

If we accept, therefore, that $f=\mathrm{I}$ then the ratio of $\frac{\mathrm{V}_{\mathrm{B}}}{\mathrm{V}_{\mathrm{T}}}$ measures heritability in the broad sense, that is

$$
\frac{V_{B}}{V_{T}}=\frac{12 D_{R}+\frac{1}{4} H_{R}}{\int_{2} D_{R}+\frac{1}{4} H_{R}+E_{1}}
$$


The same analyses carried out on ambulation and mature body weight are summarised in table 2. These yield similarly high values for the ratio of $\frac{V_{B}}{V_{T}}$ (see table 2) which are again compatible with high values

TABLE 2

Analyses of variance of ambulation and mature body weight

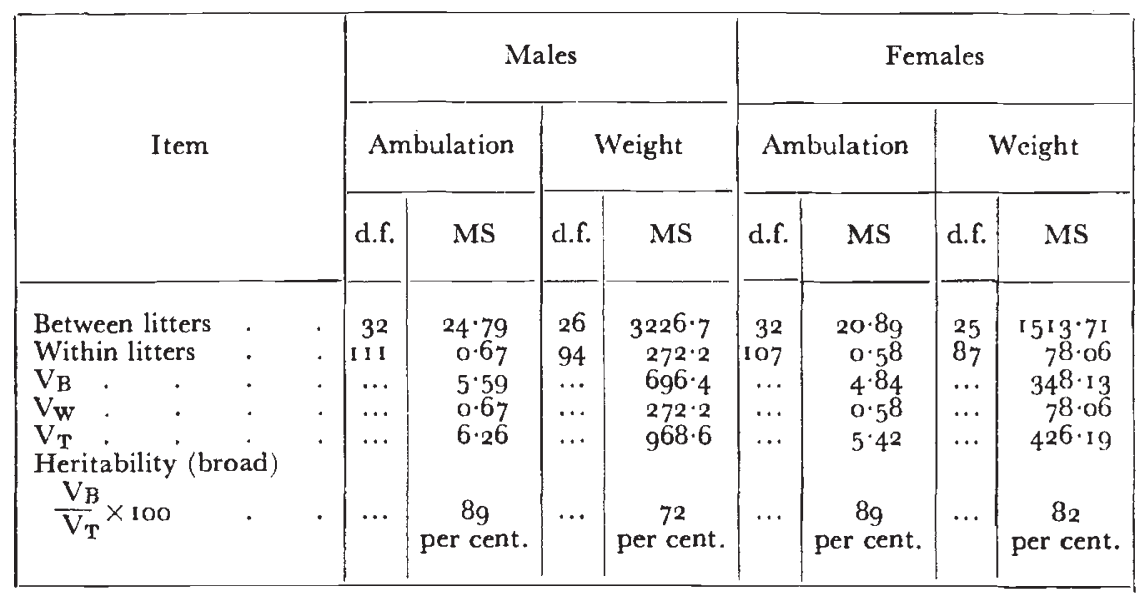

for $f$ and for heritability. However, the fact that we have assumed throughout these analyses that $\mathrm{E}_{2}=\frac{1}{n} \mathrm{E}_{1}$ may in part be responsible for these extremely high values for the heritability.

We can proceed further either

(i) by examining parent/offspring relationships (analysis of familial correlation), or

(ii) by subdividing the variation between litters on the basis of half-sib relationships through the father, or the mother or both parents (nested designs).

Familial correlation. For defecation and ambulation both parental scores are available for only 70 of the male and 64 of the female offspring. For mature body weight we have both parental scores for all of the 120 male and I 3 female offspring surviving to maturity. The four possible parent/offspring correlations, that is father-son, father-daughter, mother-son and mother-daughter and the midparentoffspring correlations are given for each of the measures in table 3 .

There are clear differences between sexes and between measures in the magnitude of the parent/offspring correlation. For defecation and ambulation the correlations with mothers are higher, suggesting a maternal effect, but no such effect is evident for mature body weight nor is it supported by later analyses of the behavioural scores. Since the father-son correlations are not the smallest there is no suggestion 
of sex linkage in the pattern of differences between the correlations (Mather and Jinks, I963).

The magnitude of these correlations depends once more on the value of $f$. Thus the general form of the parent/offspring covariance

TABLE 3

Parent/offspring correlations and narrow heritabilities derived from them

\begin{tabular}{|c|c|c|c|c|c|c|}
\hline & \multicolumn{6}{|c|}{ Offspring } \\
\hline \multirow[t]{2}{*}{ Parent } & \multicolumn{2}{|c|}{ Defecation } & \multicolumn{2}{|c|}{ Ambulation } & \multicolumn{2}{|c|}{$\begin{array}{l}\text { Mature body } \\
\text { weight }\end{array}$} \\
\hline & Male & Female & Male & Female & Male & Female \\
\hline $\begin{array}{l}\text { Father } \\
\text { Correlation } \\
\text { Heritability (per cent.) }\end{array}$ & $\begin{array}{c}0 \cdot 34 \\
4^{8}\end{array}$ & $\begin{array}{c}-0 \cdot 3^{8} \\
-54\end{array}$ & $\begin{array}{l}-0.3^{8} \\
-54\end{array}$ & $\mid \begin{array}{c}-0 \cdot 30 \\
-4^{2}\end{array}$ & $\begin{array}{c}0.44 \\
62\end{array}$ & $\begin{array}{c}0.67 \dagger \\
95\end{array}$ \\
\hline $\begin{array}{l}\text { Mother } \\
\text { Correlation } \\
\text { Heritability (per cent.) }\end{array}$ & $\begin{array}{c}0 \cdot 46 \\
65\end{array}$ & $\begin{array}{c}o \cdot 59 \\
83\end{array}$ & $\begin{array}{l}\text { o.79 } \\
\text { III* }\end{array}$ & $\begin{array}{c}0 \cdot 24 \\
34\end{array}$ & $\begin{array}{c}\mathbf{0} \cdot 23 \\
33\end{array}$ & $\begin{array}{l}0 \\
0\end{array}$ \\
\hline $\begin{array}{l}\text { Mid-parent } \\
\text { Correlation } \\
\text { Heritability (per cent.) }\end{array}$ & $\begin{array}{c}0.42 \dagger \\
59\end{array}$ & $\begin{array}{c}0.04 \\
6\end{array}$ & & $4^{1}$ & & \\
\hline
\end{tabular}

* A value greater than roo per cent. is, of course, theoretically impossible, and could only arise as a result of sampling variation.

$\dagger$ Significant at $\mathbf{P}<0 \cdot 05$.

is $\mathrm{W}_{\mathrm{P} / \mathrm{O}}=\frac{1}{4}(\mathrm{r}+f) \mathrm{D}+\frac{1}{4}(\mathrm{r}-f) \mathrm{H}_{1}-\frac{1}{4}(\mathrm{r}-f) \mathrm{H}_{2}-\frac{1}{4} \mathrm{~F}$ (Dickinson and Jinks, I956) where

$$
\begin{aligned}
& \mathrm{D}=\Sigma_{4 u v d^{2}} \\
& \mathrm{H}_{1}=\Sigma_{4} u v h^{2} \\
& \mathrm{H}_{2}=\Sigma_{\mathrm{I}} 6 u^{2} v^{2} h^{2}=\mathrm{H}_{\mathrm{R}} \\
& \mathrm{F}=\Sigma 8 u v(u-v) d h \quad \text { (Jinks, 1954) }
\end{aligned}
$$

The limiting cases are then

$$
\begin{aligned}
& \left.f=\mathrm{r} \text {, and } \mathrm{W}_{\mathrm{P} / \mathrm{o}}=\frac{1}{2} \mathrm{D}-\frac{1}{4} \mathrm{~F} \quad \text { (Jinks, I } 954\right) \\
& f=\mathrm{o} \text {, and } \mathrm{W}_{\mathrm{P} / \mathrm{o}}=\frac{1}{4}\left(\mathrm{D}+\mathrm{H}_{1}-\mathrm{H}_{2}-\mathrm{F}\right)=\frac{1}{4} \mathrm{D}_{\mathrm{R}} \quad \text { (Mather, 1949). }
\end{aligned}
$$

It is worth noting in passing that, when $f>0$, parent/offspring relationships and, indeed, variation among parental lines cannot be expressed in terms of the random mating forms of $\mathrm{D}$ and $\mathrm{H}$, that is, $\mathrm{D}_{\mathrm{R}}$ and $\mathrm{H}_{R}$, and we must use the forms appropriate for the diallel analysis (Jinks, 1954; Dickinson and Jinks, 1956; Barrai et al., ig64).

In the absence of dominance, the expected value of the parent/ offspring covariance is twice as high when $f=\mathrm{I}$ (to which it essentially approximates in these data) as when $f=0$. If, therefore, we accept $f=\mathrm{I}$, the value of the parent/offspring correlation for complete 
heritability is 0.71 . Hence for the twelve positive correlations in table 3 , heritability ranges from 6 to ioo per cent. These, of course, are estimates of heritability in the "narrow sense". We would therefore expect them to be lower on average than the earlier estimates if dominance is present. Furthermore, we would also expect them to be lower because in estimating the parent/offspring correlation we are making no assumption about the relative magnitudes of $E_{2}$ and $\frac{E_{1}}{n}$.

While on average these estimates of heritability in the narrow sense are, as expected, smaller than those given in tables I and 2, the majority are still high enough to suggest a substantial additive genetical component of variation. However, because of the relatively small number

TABLE 4

Analyses of variance of defecation scores according to paternity (nested design)

\begin{tabular}{|c|c|c|c|c|}
\hline \multirow{2}{*}{ Items } & \multicolumn{2}{|c|}{ Males } & \multicolumn{2}{|c|}{ Females } \\
\hline & d.f. & MS & d.f. & MS \\
\hline $\begin{array}{l}\text { Between fathers } \\
\text { Within fathers (between mothers) } \\
\text { Within litters. }\end{array}$ & $\begin{array}{l}12 \\
18\end{array}$ & $\begin{array}{l}3 \cdot 807 \\
8 \cdot 245\end{array}$ & $\begin{array}{l}12 \\
18\end{array}$ & $\begin{array}{l}\mathrm{x} \cdot 858 \\
\mathrm{o} \cdot 834\end{array}$ \\
\hline Within litters & 105 & 0.809 & 99 & $0.17 i$ \\
\hline
\end{tabular}

of parents involved few are significant. The three negative estimates, which are not significantly different from zero, arise in those cases where the smallest number of parents are involved and hence, presumably, reflect the greater sampling error of these estimates. In the absence of maternal effects and sex linkage the mid-parent correlations, which are all positive, provide the most sensitive test for heritability.

Nested design. By grouping the litters according to their fathers, that is, by recognising the nested design, we can partition the between litter sums of squares (table I) into a sum of squares for differences between fathers and a residual sum of squares which depends on differences between litters with the same father but with different mothers. Analysis of variance of the defecation measure employing this subdivision is shown in table 4 .

Because different numbers of females were crossed to each male (see scction 2 above) and the sizes of litters born to each mother also differ, we have no exact test of significance for differences between fathers (see Snedecor, 1956, p. 271). The reason is that the coefficient of $\sigma_{\mathrm{N}}^{2}$ (the "Between mothers, within fathers" component of variation) differs in magnitude as between the expectation of the mean square for the "Between fathers" and for the "Between mothers, within fathers "items and indeed is always larger in the former. Nevertheless, these two values for this coefficient can be determined and used to obtain independent estimates of $\sigma_{\mathrm{M}}^{2}$ and $\sigma_{\mathrm{F}}^{2}$ (see Snedecor, 1956). 
For both males and females the "Within fathers" mean square is significant. If we assume that the heritable component includes only additive and dominance effects, then the expected means squares can be expressed in terms of $D_{R}$ and $H_{R}$.

Thus

$\sigma_{\mathrm{F}}^{\frac{2}{(B e t w e e n ~ f a t h e r s)}}=\frac{(1+f)}{8} \mathrm{D}_{\mathrm{R}}$

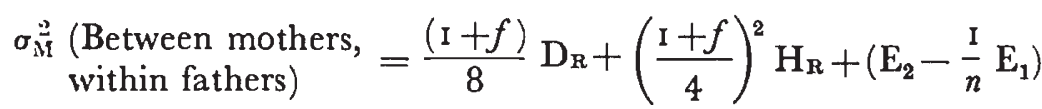

$\sigma_{\mathrm{W}}^{2}$ (Within litters) $\quad=\frac{(\mathrm{I}-f)}{4} \mathrm{D}_{\mathrm{R}}+\frac{(\mathrm{I}-f)(3+f)}{\mathrm{I} 6} \mathrm{H}_{\mathrm{R}}+\mathrm{E}_{\mathbf{1}}$.

The observed values for these three mean squares are

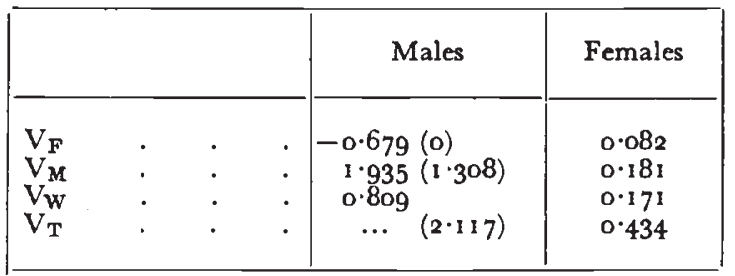

From which we obtain, by assuming that $f=\mathrm{I}$,

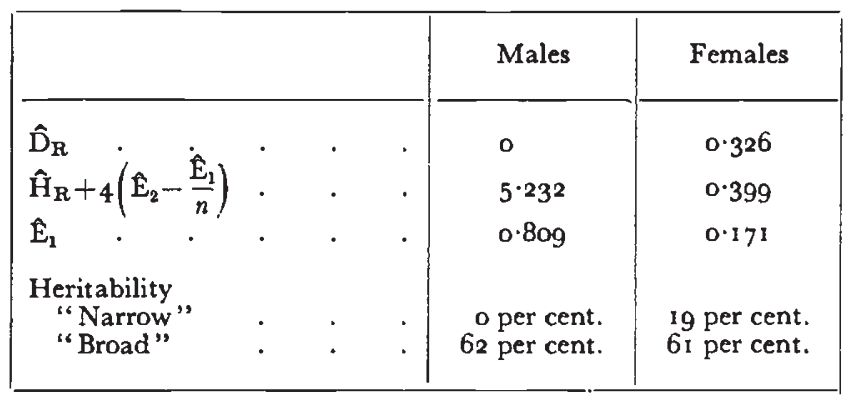

$V_{F}$ is not significantly different from zero for males and hence it has been equated with zero to obtain $\hat{\mathrm{D}}_{\mathrm{R}}$, etc., and the re-estimates of $\mathrm{V}_{\mathrm{M}}$, etc. are given in brackets.

The comparable analyses of ambulation scores and mature body weight are summarised in table 5 .

The advantages of this nested design, involving common fathers over the earlier ones can be seen by comparing the estimates given above and in table 5 with those in tables 1,2 and 3 . Thus, the nested design provides an estimate of $D_{R}$ unconfounded with dominance or environmental variation. Therefore it provides an estimate of " narrow" heritability that is not inflated by environmental variation. Of the earlier analyses only the parent/offspring relationship achieved this. In addition it provides estimates of dominance effects and broad 
heritability which, while biased, are as good as those yielded by the earlier analyses.

Although the nested design is, overall, as good as or better than the earlier analyses combined, it is, nevertheless, not without defects. Thus, any estimate of $\mathrm{H}_{R}$ or " broad" heritability it provides is inflated by environmental variation using standard animal husbandry;

TABLE 5

Analyses of variance of ambulation and mature body weight for the nested design averaged over sexes

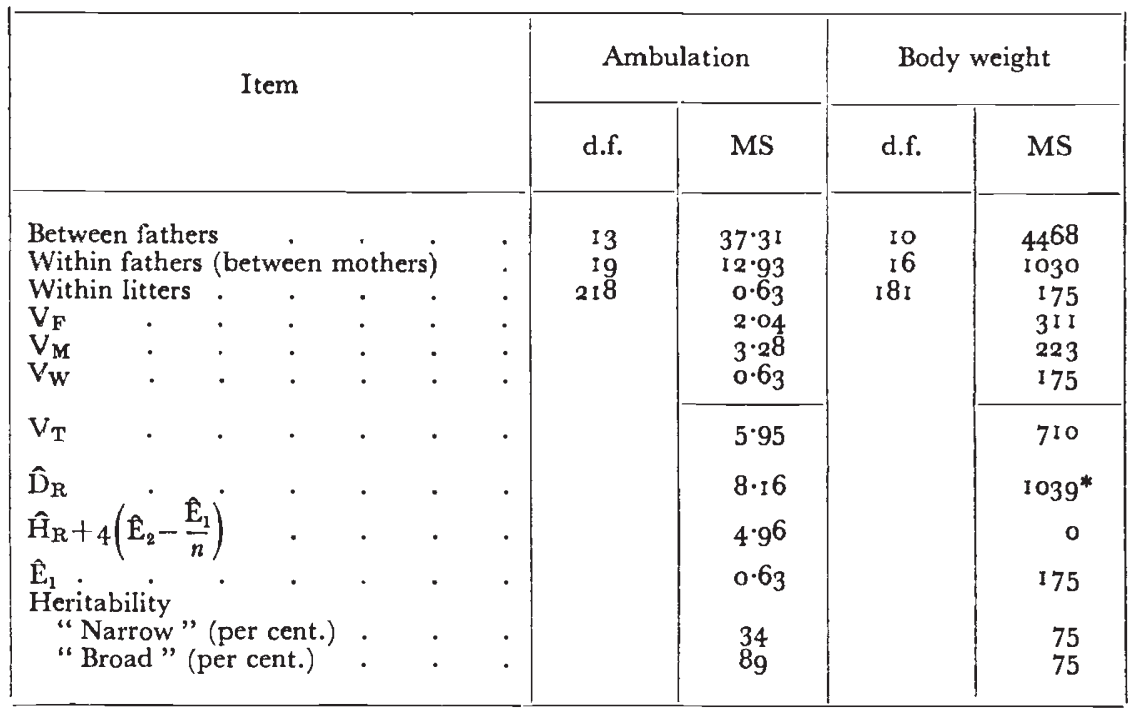

* Estimated assuming $\hat{\mathrm{H}}_{\mathrm{R}}+4\left(\mathrm{E}_{2}-\frac{\hat{\mathrm{E}}_{1}}{n}\right)=0$.

it provides no estimate of maternal effects; it assumes that the additive variation traceable to either parent is equal; and it provides no estimate of $E_{2}$, and hence no test of the equality of $E_{2}$ and $\frac{E_{1}}{n}$.

Diallel of individuals. Some of these shortcomings can be overcome by using small $2 \times 2$ diallels (Lerner, I958). They must be small, of course, because we cannot use any female for more than two or three successive matings without difficulties (see sections 2 and 3.i). For the defecation measure our data provide four $2 \times 2$ diallels and two $2 \times 3$ partial diallels in which each of the males were mated with the same three females. Each $2 \times 2$ table provides 3 degrees of freedom from differences between litters; I d.f. is for paternal differences, I d.f. for maternal differences and I d.f. for their interaction. Similarly, the $2 \times 3$ table provides 5 d.f. of which 2 d.f. are for maternal differences, I for paternal differences and the remaining two for interactions. There are, of course, a further 5 degrees of freedom for differences between 
tables. Since these have no expectation on the biometrical model described below they are omitted from the analyses of variance of the diallel tables presented in table 6 .

TABLE 6

Analysis of variance of the $2 \times 2$ and $2 \times 3$ diallel for defecation scores

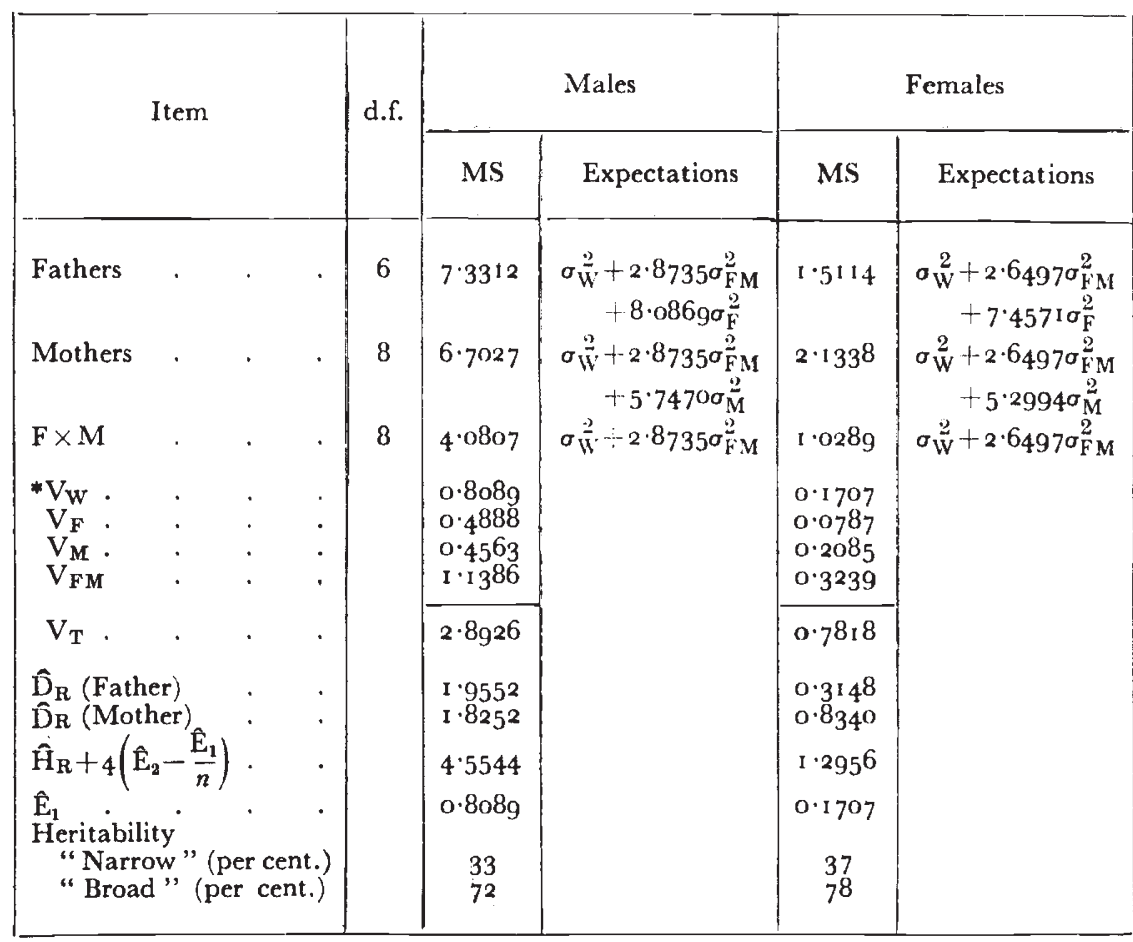

* From nested design table 4 .

If we assume once more an additive, dominance model the expectations of $\sigma_{\mathrm{F}}^{2}, \sigma_{\mathrm{M}}^{2}$ and the interaction $\sigma_{\mathrm{FM}}^{2}$ are as follows:

$$
\begin{aligned}
\sigma_{\mathrm{F}}^{2} & =\frac{(\mathrm{I}+f)}{8} \mathrm{D}_{\mathrm{R}} \text { (Mother) } \\
\sigma_{\mathrm{M}}^{2} & =\frac{(\mathrm{I}+f)}{8} \mathrm{D}_{\mathrm{R}} \text { (Father) } \\
\sigma_{\mathrm{FM}}^{2} & =\left(\frac{\mathrm{I}+f}{4}\right)^{2} \mathrm{H}_{\mathrm{R}}+\mathrm{E}_{2}-\frac{\mathrm{I}}{n} \mathrm{E}_{1} .
\end{aligned}
$$

If we accept once more our estimate that $f=\mathrm{I}$, we arrive at the estimates of the components shown in table 6. The estimate of $\sigma_{\mathrm{w}}^{2}$ and of $E_{1}$ given is that from the nested design (table 4). The estimates provided by the diallels give a more comprehensive picture than any of the earlier analyses. They provide an estimate of additive differences 
between parents but no clear evidence for a difference between mothers and fathers in respect of its magnitude. This finding does not support the somewhat higher parent/offspring correlation for maternal than for paternal parents. Hence there is no evidence of maternal effects or of differences between parents in their heritable contributions to their progenies. This design, however, still fails to provide an estimate of dominance which is not inflated by inequalities between $E_{2}$ and $\frac{E_{1}}{n}$. Indeed the large value of $\mathrm{H}_{\mathrm{R}}+4\left(\mathrm{E}_{2}-\frac{\mathrm{E}_{1}}{n}\right)$ relative to all other components suggests that $E_{2}$ may be considerably greater than $\frac{E_{1}}{n}$.

TABLE 7

Analysis of the $2 \times 2$ and $2 \times 3$ diallels for ambulation and mature body weight averaged nver sexes

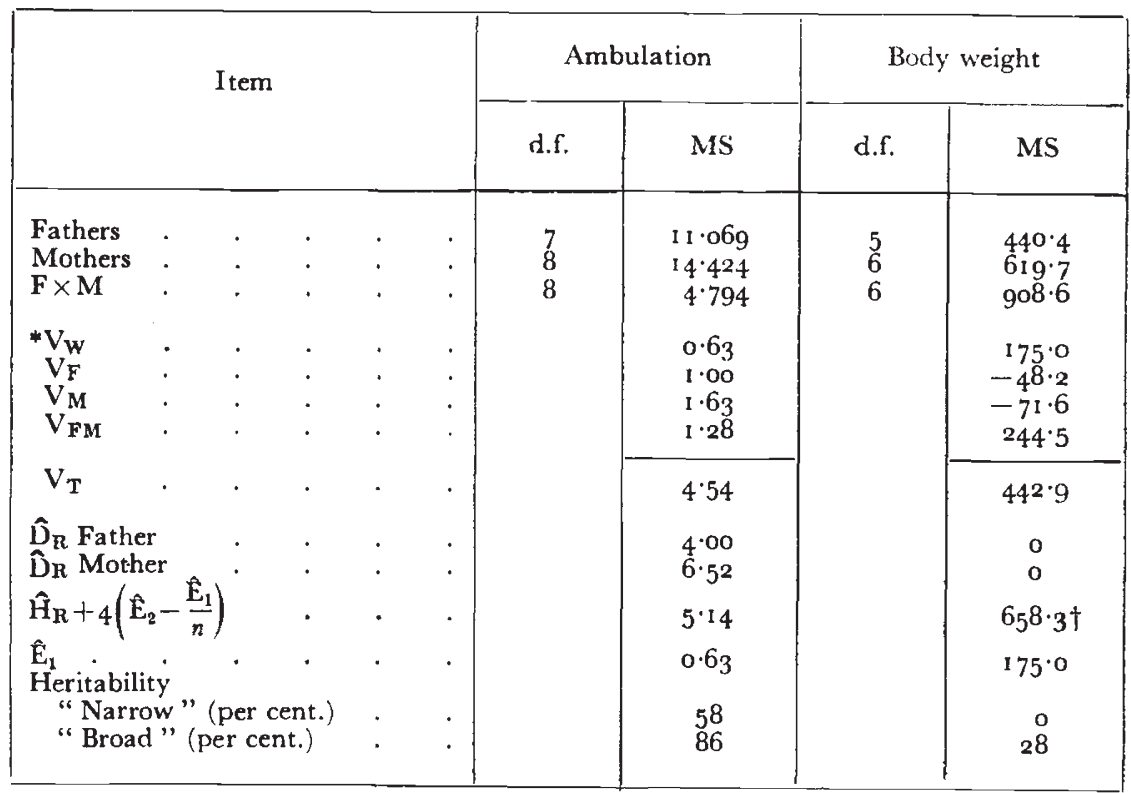

* From nested design.

$\dagger$ Estimated after putting $V_{F}=V_{M}=0$.

In the absence of maternal effects we can obtain estimates of "narrow" and "broad" heritabilities whose expectations and interpretations are the same as for the nested design. These estimates, which are in good agreement with the estimates from the nested design, are also given in table 6 . All are positive and agree between sexes. A summary of the outcome of applying the analysis illustrated from the defecation scores to the other measures is given in table 7. They in no way alter our broad conclusions. 


\section{COMPARISONS BETWEEN ANALYTICAL METHODS}

We have now analysed the components of variation in the same population of rats by four methods, namely:

I. Variation within and between litters produced by random mating,

2. Parent/offspring correlation in random mating,

3. Nested design using common fathers, and

4. Diallel crosses using individuals as the unit of crossing.

In addition the inheritance of the same characters in a diallel table of crosses using six inbred strains of rats drawn from the same basic

TABLE 8

Potential differences between five experimental designs applicable to analyses possible with laboratory rats

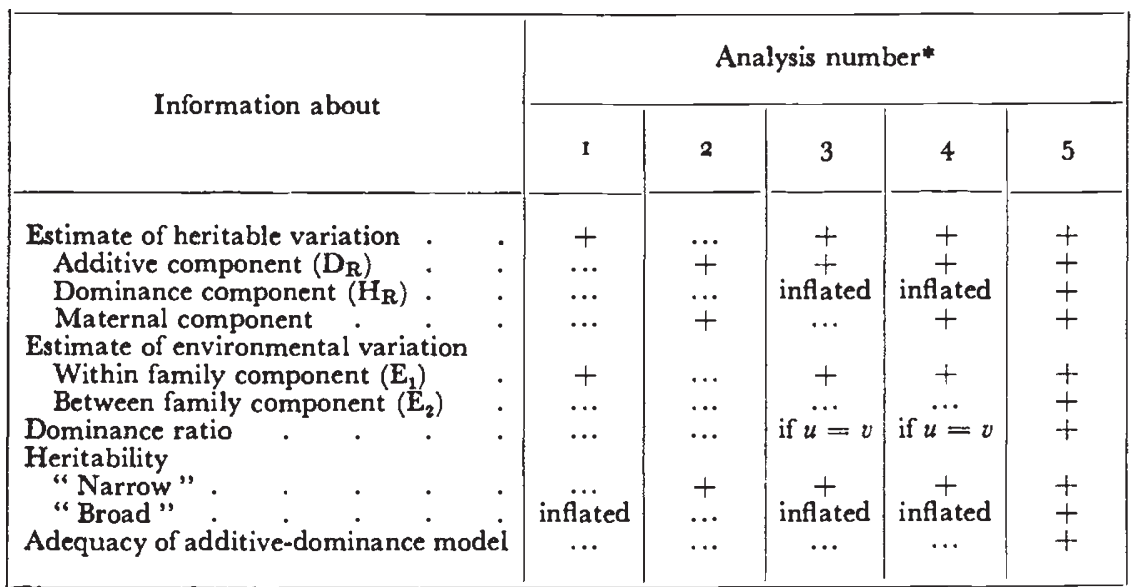

* $1=$ Within and between litter variation.

$2=$ Familial correlation.

$3=$ Nested design.

$4=$ Diallel of individuals.

$5=$ Diallel of strains.

Notes-

+ means method is potentially capable of giving estimate.

"inflated "means method is potentially capable of giving estimate, but with designs imposed by the material the estimate will be inflated by inequality of $E_{2}$ and $\frac{E_{1}}{n}$.

"if $u=v "$ means that $\sqrt{\overline{\mathrm{H}_{\mathrm{R}}}}$ provides estimate of dominance ratio, $\sqrt{\bar{\Sigma} h^{2}}$, if gene frequencies are equal at all loci.

pool of material has been determined in earlier investigations (Broadhurst, I96o; Jinks and Broadhurst, 1963). We are, therefore, in a position to compare five analytical procedures.

Their potential value in situations like that presented in experiments with laboratory rats is summarised in table 8 . Clearly, the $6 \times 6$ diallel between inbred strains provides most information with the individual diallels coming a clear second. It is equally clear, however, that the 
limiting factor in designs $\mathrm{I}$ to 4 is the absence of an estimate of $\mathbf{E}_{2}$. This can be overcome either

(i) by replication of matings, or

(ii) by separating members of the same family and rearing them as independently randomised individuals each in a separate cage.

The first method provides an estimate of $E_{2}$ but it creates difficulties in the absence of inbred lines because replication requires the use of the same mother more than once for the same mating. The inability to use the same mother repeatedly already constitutes a limiting factor in all the designs discussed.

The second method attempts to minimise the discrepancy between $\mathrm{E}_{2}$ and $\frac{\mathrm{E}_{1}}{n}$ and is already in use in comparable plant breeding programmes to achieve this result (Kearsey, 1964; Lawrence, 1965). In mammals, however, the breaking up of family units is limited by the duration of the period of essential maternal care. In rats, for example, weaning occurs around 2 I days and hence we cannot normally separate individual animals until this date. Having shared a common environment for the first 2 I days would mean that the environmental component of variation for members of the same litter would lie somewhere between $n \mathrm{E}_{2}$ and $\mathrm{E}_{1}$, while that for members of different litters would still be $n \mathrm{E}_{2}$. In any case randomly allotting members of the same litter to different cages would not minimise the non-heritable variation between members of different litters that arises from being born at different times or to mothers of different ages, parities and weights. It would appcar, therefore, that with small, polytocous, laboratory animals we have two practical choices if we wish to overcome the problem: either (i) to raise genuine replicate progenies for a proportion of the crosses, which can be randomly or systematically chosen (cf. Design III of Miller et al., I963), or (ii) to include samples of highly inbred material and the $F_{1}$ crosses between them into the experiment as controls to estimate the relative sizes of $\mathrm{E}_{1}$ and $n \mathrm{E}_{2}$. We can then use any of the four crossing programmes described in this paper and correct them for the discrepancy between $\mathrm{E}_{1}$ and $n \mathrm{E}_{2}$ using the observed $\mathrm{E}_{1}$ and the ratio of $\mathrm{E}_{1}$ to $n \mathrm{E}_{2}$ obtained from the inbred and $\mathrm{F}_{1}$ families.

Although not conducted entirely simultancously, the diallel cross between six inbred strains of rats carried out in the same laboratory as the present investigation provides us with the necessary information to estimate the ratio of $\mathrm{E}_{1}$ and $n \mathrm{E}_{2}$. For defecation score the ratio is approximately I :2. Accepting this value leads to corrected estimatcs of 3.4284 and 0.9380 for $H_{R}$ in males and females, respectively (see table 6).

Although there are a few internal inconsistencics, such as zero heritabilities (tables 3 and 7), most of the analyses, the results of which are summarised in table 9, demonstrate a heritable component of 
variation for each of the three measures we have considered. Equally, because of the confounding of dominance with non-heritable variation between members of different litters, none of the analyses has provided unambiguous evidence of dominance effects of the genes controlling

TABLE 9

A comparison of the narrow and broad heritabilities (in per cent.) obtained for the three different measures by the different analyses

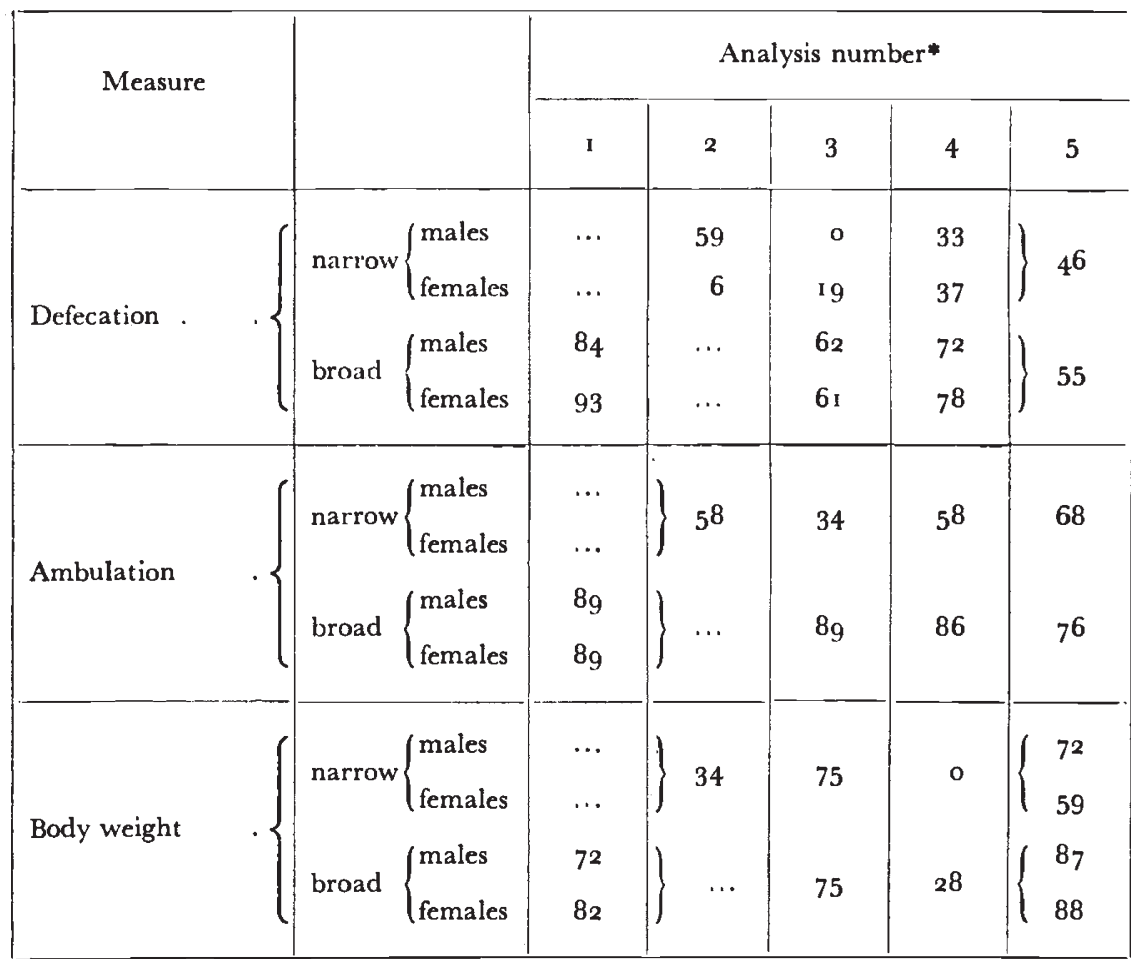

* $\mathbf{I}=$ Within and between litter variation.

2 = Familial correlation.

$3=$ Nested design.

$4=$ Diallel of individuals.

$5=$ Diallel of strains. (Values given in the table are included for comparison and are derived by means of the same formula from estimates of the components of variation obtained by Broadhurst (1960) for defecation and ambulation and Jinks and Broadhurst (1963) for body weight.)

the characters. That this confounding has, as expected, led to an overestimation of broad heritability is shown by the fact that estimates of broad heritability from the diallel between strains (table 9, analysis 5) which do not suffer from this defect are, on the whole, lower than those obtained from the other analyses. Three of the analyses, namely, the parent/offspring correlation, the nested design and the diallels of individuals, on the other hand, provide clear evidence of additive action of the genes controlling the two behavioural traits and mature body weight. As far as the latter measure is concerned, however, little 
advantage has been gained from adopting the nested or diallel designs. For the behavioural measures, however, the evidence for the absence of maternal effects and for additive gene action comes more clearly from the diallel design than from the others even though a sizeable fraction of the data has been sacrificed in omitting crosses that do not fit this design.

In all the analyses described in this paper we have had to assume, without any internal supporting evidence, that an additive, dominance model of the heritable variation is adequate although, of course, we could not have fitted a more complex model using these analyses even if we had had cause to doubt its validity. From the analyses of diallels between strains and of crosses between pairs of strains continued to the $\mathrm{F}_{2}$ and first backcross generations; both of which provide tests of the model, we have no reason to doubt that such a model is adequate for ambulation and mature body weight (Broadhurst, 1960; Jinks and Broadhurst, 1963). For defecation, however, application of these tests showed that a transformation of the data was necessary before this simple model could be regarded as adequate. The inability to apply such tests to the other analyses probably constitutes their greatest weakness.

It is difficult to arrive at a mean estimate of narrow heritability for the three characters but, if we look at the three designs that provide an estimate, the order of decreasing heritability for the three characters is on average ambulation, mature body weight then defecation. Thus we find once more (cf. Broadhurst, I96o; Broadhurst and Jinks, 196r) that behavioural traits have heritable components that are quite as high if not higher than morphological characteristics, thus adding further evidence-if such were still needed-to our contention that the methods of biometrical genetics are fully applicable to the behavioural phenotypes encountered in psychogenetics.

\section{APPLICATION TO PRIMATES}

So far we have discussed the various analytical techniques in terms of small laboratory mammals where in most instances time and effort can produce inbred strains and hence most of the problems we have discussed can be overcome. However, the original purpose of this investigation was to consider the usefulness of these analytical techniques for animals, such as primates, where there is no immediate prospect of carrying out long-term inbreeding programmes. Moreover, we have found that nested and diallel designs are adventitiously used in the routine maintenance of primate colonies. Thus, in one established primate colony, a few males of proved fertility sired many offspring from a large range of females. Since partnerships were not consistently maintained in successive years, it so happened that two complete $3 \times 3$ diallel crosses of individuals, as well as an incomplete $4 \times 4$ diallel, together with a large number of overlapping, though individually unique, $2 \times 2$ diallels were generated in this way. In addition, 
replicated arrays abounded. Unfortunately, none of the available behavioural measures was common to a substantial number of parents and of offspring, and the only measure common to all offspring (birth weight) was so confounded with a parity effect as to be valueless for genetic analysis (Broadhurst and Jinks, I964a). These findings nevertheless suggest that a search for such replicated arrays and small diallels resulting from multiple marriages in human populations might be rewarding.

However, a further difficulty occurs. When the majority of births are single, there is no within family mean square of the kind that arises with multiple births. We have therefore only two possible estimates of the within family component of variation, viz. (i) replicate matings (ii) the rare cases of multiple births, such as mono-dyzygotic. twins, etc.

Replicate mating is possible although it increases the time duration of the experiment and reduces the number of different mates that any one mother can have. As we have seen repeated use of the same mother can lead to parity and related differences which for certain morphological characteristics in monkeys and in man can be marked. This renders replicate mating useless as an estimate of purely within family variation unless a correction for time effects such as parity can be applied.

Monozygotic twins reared together provide an estimate of $E_{1}$ and reared apart provide an estimate of $E_{2}$. Both estimates, however, are liable to be atypical in that twins raised simultaneously in time, whether in the same family or in different families, will be subjected to a smaller range of environmental variation than, for example, siblings which are raised in succession.

To summarise, therefore, the $2 \times 2$ diallel of individuals is superior to the nested design which in turn is better than single pair mating for determining components of phenotypic variation. However, all suffer from common difficulties when applied to outbreeding material in that an estimate of $f$ is required to estimate the components of the simplest additive-dominance model of the heritable variation and no method of comparing $E_{2}$ and $E_{1}$ is available that does not lead to practical difficulties using most mammals. The extent to which this invalidates any conclusions about dominance and broad heritability can be determined only empirically, although both must be inflated if $E_{2}>\frac{E_{1}}{n}$.

\section{SUMMARY}

I. A number of simple biometrical analyses are available for studying the inheritance of behaviour when the animals available for crossing, or who have been adventitiously mated together already, are a collection of miscellaneous individuals of varying or even unknown relationships.

2. Four of these analyses (i) within and between litter variation, 
(ii) familial correlation, (iii) nested designs (common fathers) and (iv) small diallel crosses of individuals are described. Their advantages and disadvantages for estimating components of variation and heritabilities are illustrated by reference to two behavioural measures and the adult body weights of 336 offspring obtained by mating 14 males and 17 female rats.

3. All the analyses except (i) provide unbiased estimates of additive variation but none provides an estimate of dominance variation that is not inflated by non-heritable sources of variation between litters. Modifications in the experimental designs which would overcome this limitation are described and their practicability for small mammals and for primates discussed.

4. Overall, the most informative analysis proved to be (iv) followed by (iii) but all fall short of the analyses that are possible when breeding programmes are based on inbred strains.

5. The prospects of applying improved analyses (iii) and (iv) to primate colonies and human populations are discussed.

\section{REFERENCES}

B.ARrai, I., CAVAlli-Sforza, L. L., AND mainardi, M. 1964. Testing a model of dominant inheritance for metric traits in man. Heredity, $19,65^{1-668 .}$

BROADHURST, P. L. 1959. Application of biometrical genetics to behaviour in rats. Nature, Lond., 184, I517-1518.

Broadhurst, P. L. 1960. Experiments in psychogenetics. Application of biometrical genetics to the inheritance of behaviour, I-I02. In Eysenck, H. J. (ed.), Experiments in Personality, Vol. I. Psychogenetics and Psychopharmacology. Routledge and Kegan Paul, London.

BROADHURST, P. L., AND JiNKS, J. L. I961. Biometrical genetics and behaviour: reanalysis of published data. Psychol. Bulletin, $5^{8}, 337-362$.

BROADHURST, P. L., AND JINKS, J. L. 1963. The inheritance of mammalian behaviour re-examined. Journ. of Heredity, 65, 170-1 76 .

BROADhURST, P. L., AND JiNks, J. L. $1964 a$. Parity as a determinant of birth weight in the rhesus monkey. Folia Primatologia (in press).

BROADHURST, P. L., AND JinKs, J. L. 1964 $b$. Stability and change in the inheritance of behaviour: a further analysis of statistics from a diallel cross (in preparation).

Cockerham, c. C. 1956. Analysis of quantitative gene action. Genetics in plant breeding. Brookhaven Symp. Biology, 9, 53-68.

DICKINSON, A. G., AND JiNKs, J. L. 1956. A generalized analysis of diallel crosses Genetics, 4I, 65-78.

FALCONER, D. S. Ig6o. Introduction to Quantitative Genetics. Oliver and Boyd. Edinburgh.

FUller, J. L., AND thompson, W. R. 1960. Behavior Genetics. John Wiley \& Son Inc., New York.

JINKS, J. L. 1954. The analysis of continuous variation in a diallel cross of Nicotiana rustica varieties. Genetics, 39, 769-788.

JiNks, J. L., AND bRoAdhuRst, P. L. 1963. Diallel analysis of litter size and body weight in rats. Heredity, $18,319-336$.

KeArsey, M. J. 1964. Variation in populations of Drosophila and Papaver. Ph.D. Thesis, University of Birmingham Library.

Kempthorne, o. 1957. An Introduction to Genetic Statistics. John Wiley \& Son Inc., New York. 
LAWREnce, M. J. 1965. Variation in wild populations of Papaver dubium. Heredity (in press).

LERneR, I. M. 1958. The Genetic Basis of Selection. John Wiley \& Son Inc., New York.

MATHER, K. 1949. Biometrical Genetics. Methuen, London.

MATHER, K., AND JINKs, J. L. 1963. Correlations between relatives arising from sex linked genes. Nature, Lond., $198,314-315$.

MILlER, R. H., LESATES, J. E., AND COCKERHAM, C. C. 1963. Estimation of nonadditive hereditary variance in traits of mice. Genetics, $48,177-188$.

SNedecor, G. W. 1956. Statistical Methods. The Iowa State College Press, Ames, Iowa.

WRIGHT, S. 1921. System of mating: II. Genetics, 6, 124-143. 